\title{
In-service supervision of a beginning teacher as a condition for the continuity of professional development
}

\author{
E.Yu. Ilaltdinova ${ }^{1 *}$, S.V. Frolova ${ }^{2}$, and T.N. Sergeeva ${ }^{3}$ \\ ${ }^{1}$ Kozma Minin Nizhny Novgorod State Pedagogical University (Minin University), Nizhny \\ Novgorod, Russia \\ ${ }^{2}$ Kozma Minin Nizhny Novgorod State Pedagogical University (Minin University), Nizhny \\ Novgorod, Russia \\ ${ }^{3}$ Kozma Minin Nizhny Novgorod State Pedagogical University (Minin University), Nizhny \\ Novgorod, Russia
}

\begin{abstract}
The article is devoted to the problem of organizing in-service supervision of a beginning teacher in educational environment. The conceptual and practical ways of designing the model of in-service supervision of a young teacher are analyzed in the article. In-service supervision is defined as a purposeful complex process involving the cooperation of teachers-mentors with a young specialist in order to ensure successful entry into the profession, effective teaching, adaptation to the professional environment and overcoming crises and barriers arising in the process of teaching. The model of in-service supervision is based on a convention generation approach. A set of complementary principles of organizing in-service supervision is described. The model of in-service supervision is founded on the institution of double mentoring: a mentor from teachers' education university staff and a mentor from school supervise a beginning teacher. The in-service supervision is based on mentoring technology. The authors describe the developed website for online in-service supervision, allowing timely, prompt interaction with a young teacher. The article analyzes the system of criteria for choosing a mentor as well as the system of professional and personal qualities of a mentor.
\end{abstract}

\section{A problem statement}

The educational environments need sustained and strong mechanisms for effective intergenerational professional interaction among the teaching staff in order to form a community of professional teachers who enter the profession after graduating from teacher training programs. Modernization of teacher education in Russia makes the problems of providing support for the life cycle of the teaching profession very acute. The range of the problems is wide. These are: effective entry of graduates into the profession, their initial

*Corresponding author: prof-ped.gpa@mail.ru 
adaptation in the workplace, retention and consolidation in professional activities, on the one hand, and on the other hand, ensuring the continuity of in-service professional development of experienced teachers in order to maintain their professional well-being and overcome the risks of professional burnout.

The first years in the profession for a novice teacher are often called the "survival time" [1] due to emerging professional crises, which are often difficult for a teacher who lacks experience to cope with on their own. Special conditions organized for supervising the early years in the teaching profession affect the retention rate in the profession of novice teachers, alongside with shaping their professional identity and professional well-being.

The reflexive model of teacher professional development includes three main stages. The first stage is professional training at the university. The second is the primary practical application of the obtained theoretical training while entering the profession. The third stage is the development of professional skills based on the effectiveness of the second stage. The role of specially organized in-service supervision is important at the second stage, when the novice teacher is at the stage of acquiring professional experience and understanding it.

At the present moment we have to state a number of problems in this area. First, the mentoring traditions developed in the Soviet school had been gradually lost since the 1990s. Secondly, the growth of responsibilities on representatives of school administration resulted in reducing and formalizing their mentoring activity. It was preserved and developed only in some single cases.

At the same time Russian education has a long tradition of mentoring in teachers' profession. In-service supervision of a young teacher has always been and is being carried out in Russian schools in various forms. It is part of the functional carried out by school administrators. School and regional teachers' associations work with young teachers, teacher contests are developed at city, region and federal levels. The government is interested in enhancing the quality of teacher training. All this gives reasons to conclude that the perspectives of the problem under consideration are highly promising and can be applied in practice.

\subsection{The objective of the work}

The study of the state of in-service supervision in the Russian teacher education of the past decades states the lack of attention of researchers to this problem. This is confirmed by the fact that at the present stage the process of including a young specialist in the profession is not supervised by teachers education university staff and the mentoring is not sufficiently developed [2].

I.I. Cherkasova and T.A. Yarkova [3] studied the measures aimed at attracting graduates of teacher training programs to work in school. The study shows that the main attention is paid to material motivation of young teachers and insufficient attention to supervising the "entry" and engagement of young specialists in the profession. At the same time, researchers point out to the positive experience of professional adaptation of young teachers in some regions of the country. Such experience requires scientific verification, comprehension and generalization [2].

E.I. Kazakova and A.P. Tryapitsyna consider teacher supervision as helping a teacher to form the orientation field of self-development, the responsibility for the actions in which is borne by a teacher themselves [4].

E.A. Aleksandrova considers teacher supervision as a type of teaching, which is the preventive process of teaching a professional to independently plan their life paths and individual professional routes, to organize life activities, to solve problems, and to be permanently ready to respond adequately in emotionally uncomfortable situations [4]. 
Mentoring in a professional environment is quite common in some countries. Highly effective education systems (USA, Australia, UK) are committed to support novice teachers starting from the moment of entry in the profession till successful retention.

Some studies devoted to the problem of mentoring encounter the phenomenon associated with mentoring in the educational environments - the culture of professional responsibility. On the one hand it is the basic element, the foundation for the interaction of a mentor and a mentee, and on the other hand it is the result of successful mentoring practices in a professional educational environment [5]. The culture of professional responsibility forms the teaching community on the basis of professional values, principles of professional supervision and effective interaction.

A profound study on Teacher Performance [6], which involved 5,000 aspiring teachers and 1,000 experienced teachers and school principals in Victoria and Queensland (Australia) found a link between the effective organization of integrated in-service supervision and the readiness and motivation of mentors [7]. The higher the readiness and motivation of the mentor, the more successful the mentoring is and the more effectively its results are achieved. This brings us to the conclusion that to create conditions for the development of mentoring competence of teachers is most important. The skills of implementing a mentoring session, effective professional interaction, diagnosing professional crises of a novice teacher are the components of mentoring competence.

An Australian experimental study of 54 novice teachers found that mentoring contributed to the success of professional tasks performance, to the growth of professional enthusiasm and knowledge. Mentoring was viewed as a "welcome" to the profession and school at the beginning of a teacher's career [8].

The AITSL study [6] aimed at examining the effectiveness of supervision of novice teachers in the educational environment of the school. According to this study only $58 \%$ of the respondents answered that the mentor helped create conditions for the strategy of the professional growth of the young teacher. $43 \%$ of the participants answered that during the supervision special events were carried out in the allotted time (thus, the remaining 57\% faced the lack of regulation of the supervision process). Only 30\% of mentors received special training concerning mentoring competencies development.

These results of the study show that organizational conditions of in-service supervision are insufficient, which is primarily due to the lack of a clear definition of these conditions. What needs to be done by an educational organization today for in-service supervision to be effective?

This issue is topical today in Russia. We observe the intention to revive the traditions of mentoring in the Russian educational environment of Soviet times. Research centers at universities and mentoring centers are being arranged. However, mentoring is still more sporadic than systematic nowadays.

At the moment the research of in-service supervision in the context of new sociocultural and professional conditions of modern Russia is considered insufficient.

The objective of the article is to determine the conceptual provisions and practical solutions in the model of in-service supervision of a teacher in the professional environment.

\section{Results of the research}

In-service supervision is an integral part of teacher training and is a set of targeted comprehensive measures. Such measures include cooperation of teachers-mentors with beginning teachers in order to ensure successful entry into the profession, effective teaching, adaptation to the professional environment and overcoming crises and barriers, arising in the process of working as a teacher. 
In the period from 2016 to 2017, Minin University developed and tested a model of employer-sponsored teacher training, one of the elements of which is the mechanism of inservice supervision of a graduate of a teacher training program. A model of employersponsored teacher training was approved at a meeting of the Government of the Russian Federation with its head D.A. Medvedev and members of the Cabinet of Ministers and recommended for implementation in 2017. In 2016-2017 four pilot regions took part in approbation testing the model in Russia, including the Minin Nizhny Novgorod State Pedagogical University. Another 12 regions participated in the experiment in 2017 on their own initiative. Approbation of the model of employer-sponsored teacher training, including in-service supervision, showed high efficiency and withstood a comprehensive examination successfully $[9,10,4]$.

The process of in-service supervision is based on the mechanism of double mentoring [10]. The beginning teacher is supervised by a mentor from the teacher education university and by a mentor from school. The supervision is based on mentoring technology, which contributes to informational, psychological and methodological supervision, and also contributes to professional socialization of a beginning teacher. Such supervision is carried out by means of a web portal. The electronic service allows for online in-service supervision and makes interaction between mentors and a young teacher prompt and timely.

The aim of in-service supervision $[9,10,4]$ is the creation of conditions for a beginning teacher to "enter" the profession successfully and to adapt to it effectively. This is a very important stage of the teacher's professional development in the structure of the life cycle of the profession.

The objectives of in-service supervision are the following:

1. the development of graduates' competencies in teaching;

2. the conditions for overcoming crises and barriers in the profession for a beginning teacher;

3. the adaptation of the novice teacher to the school environment;

4. conditions for a sustained motivation of a beginning teacher to work at school.

In-service supervision of teachers should focus on four key areas [9]:

- $\quad$ professional skills - development of a wider range of practical skills;

- professional identity - development of concepts about effective teaching, professional responsibilities and values, and awareness of their role in students' development;

- wellbeing - development of emotional stability, a sense of professional success, the development of professional motivation and a sense of belonging to the teachers' community;

- $\quad$ professional orientation - development of knowledge about the teachers' world at the formal level (knowledge of documents on education, standards, programs) and informal (understanding cultural, social characteristics that contribute to the formation of interpersonal interaction).

The methodological basis for the model of in-service supervision is the convention generation approach (A.A. Fedorov, E.Yu. Ilaltdinova, S.V. Frolova). The socio-cultural environment of the 21 st century is characterized by a paradigmatic shift in forming relationships between the older and younger generations. The problem of generation gap acquires a fundamentally new meaning while maintaining all the universal, eternal contexts, conditions and shades of this problem. This paradigm shift is primarily determined by the qualities and characteristics of the younger generation, which distinguish it not only from the older generation, but also from the younger generations of previous eras. In their turn, the older generation is surprised to discover the number of life spheres in which they have no advantages over the younger one. This fact is accepted in different ways [11]. 
The convention generation approach is based on the principle of the "convention of generations". It is a multi-vector interaction of generations, different from traditional understanding of the one-directional interaction of generations when experience and knowledge are transferred from the elders to the younger [11]. It is based on creating the conditions for the continuous exchange of professional values and meanings in a "common destiny" (M. Heidegger) of an educational environment. The convention generation approach is based on the co-existence of a mentor and a beginning teacher mastering and designing professional environments together. The suggested approach recognizes the importance of developing not only a novice teacher, but also a mentor. Professional development of a young teacher presupposes simultaneous professional development of a mentor. Mutual development of several generations living in a single educational environment is very significant and natural for creating a teachers' team.

The convention generation approach to in-service supervision is implemented in the form of the so-called conventional practices. Unlike the classical mentoring practices of elaborating skills of a novice teacher, the mentor also gets involved in professional growth. Such interaction involves professional introspection not only of a novice teacher, but also of the mentor. Mentors evaluate their own mentoring competencies and supervision advancement and make professional discoveries.

The principles of trust, acceptance and awareness are important for building communication between different generations. The mentoring relationship involves an open type of relationship based on equality of the mentor and the novice teacher (peer-to-peer). A mentor is not a master to a young teacher, but a partner. A mentor creates conditions for a more successful and faster entry of a beginning teacher into a professional environment.

These are the results of in-service supervision a mentor should strive for: improving the quality of mentee's teaching; adaptability and "involvement" of a young teacher in the professional environment; aspiration to professional self-improvement of a beginning teacher and a long lasting motivation to teach.

A mentor in the in-service teacher supervision must be guided by the following principles. They should be implemented as a system. The four most significant principles of the in-service teacher supervision are:

- the principle of free and mutual choice of a mentor and a mentee - a team of in-service supervision is formed voluntarily on the basis of a free and mutual choice of mentors and mentees;

- the "peer-to-peer" principle - creation of a professional team, members of which perceive each other's professionalism respectfully and without any prejudices and stereotypes, evolving, and acquiring new professional experience together;

- the principle of convention of generations, contributing to mutual acceptance based on the continuous exchange of values and aspirations;

- the principle of trust and support, building confidential, open and well wishing relationships between a mentor and a novice teacher.

In-service supervision is bound to be effective if certain requirements to mentors are met.

Firstly, the mentor should have significant achievements as a teacher, which means: a high level of professionalism, availability of special knowledge and skills, and the ability to maintain professional development. The mentor should be able to assess the teacher's performance and comprehend the teaching and work of the school in a systematic way.

Secondly, the mentor should have at least 5 years of teaching experience at school, showing dedication to the school and its culture, observing professional teachers' ethics and executive discipline.

Thirdly, an experienced teacher should not only perceive the essence of a mentor's role and its advantages, but also engage in this activity willingly. That is why the success of in- 
service supervision depends mostly on the mentor's personal desire and their willingness to share professional experience, the ability to communicate ideas intelligibly and patiently, demonstrating the ways of solving professional problems.

Besides, the literature review allows singling out a number of personal qualities of a teacher which are particularly important for mentors. These are communication skills, shown in active communication and leading the initiative, emotional response to the state of communication partners, an intelligible presentation of their thoughts. Other qualities are: being organized, emotionally stable and positive. These qualities determine the ability to maintain an optimal emotional state, quickly adapt to changes and make decisions in situations of information overload. Emotionally "burnt out" teachers cannot be mentors, because first they need help themselves.

There are a number of other important professional and personal qualities of a mentor. They are the ability to plan, analyze and evaluate, to prioritize, the ability to criticize beneficially, to keep the distance, the ability to negotiate, to be an active listener, to set questions, the absence of prejudice.

The process of in-service supervision includes four stages: the stage of entry into the profession, the initial adaptation of a beginning teacher, the motivational and value stage, the stage of professional progress [10].

The main goal of the first stage of in-service supervision of novice teachers is to ensure their effective entry into the profession. Mentors' actions at the first stage include: setting the goal and the short-term perspective in teaching; supervising the teaching of at a certain school; arrangement of online supervision via a web portal; analysis of in- and out-ofschool activities of a beginning teacher; individual counseling and coaching; introspection as a form of entry reflection; diagnostics of primary crises and barriers in teaching.

The second stage of in-service supervision is aimed at successful initial adaptation of a beginning teacher. Mentors' actions at the second stage include: individual counseling; online and offline supervision; analysis of in- and out-of-school activities organized by a beginning teacher; filling up an observation diary; diagnosing the degree of adaptation of a beginning teacher to teaching.

The purpose of the third stage of in-service supervision is to form the background for a system of professional values and motives of a beginning teacher. Mentors diagnose the professional value orientations of a young teacher and the motivational structure of the personality; do individual counseling, and take part in a variety of events at school. The mentee-teacher presents personal achievements in the portfolio via in-service web portal, takes part in the online forums of professional communication.

The main aim of the fourth stage is to create conditions for the professional development of a beginning teacher. At this stage, the mentors diagnose the adaptation degree of the mentee-teacher, and build the conditions for a beginning teacher to demonstrate the personal achievements in teaching at the final event of in-service supervision.

In the process of in-service supervision mentors assess the performance of a novice teacher. The aim of this assessment is to identify a set of professional abilities, qualities and competencies acquired during the pre-service teacher training and in-service supervision. The level of the development of the set of acquired abilities, qualities and competencies indicates that the beginning teacher is ready to work effectively at school. The mentors state the main achievements in the "Chart of the beginning teacher's performance assessment".

In-service supervision of a beginning teacher in identifying and overcoming crises and barriers includes five phases: the phase of diagnose ( contact establishment, problems verbalization, the problem significance level assessment), the phase of search (a cosearching for a solution to a problem), the phase of agreement (mutual agreement on preplanned actions), the phase of action (support of the mentee's initiative, assistance and 
cooperation) and the phase of introspection (discussion, declaration, analysis of the experience).

The implementation of the described above model of in-service teacher supervision implies continuous interaction between mentors and a mentee by means of web portal (https://pdsv.mininuniver.ru/), developed and tested by Minin University in 2018.

The concept of the in-service teacher supervision web portal reflects the four stages of in-service teacher supervision and the five phases of identifying and overcoming crises and barriers of the content and the main principles of interaction in in-service supervision. This is presented in a systematic form in Table 1 .

Table 1. Interaction of participants of in-service supervision.

\begin{tabular}{|l|l|l|l|l|}
\hline \multicolumn{1}{|c|}{ Content } & \multicolumn{1}{|c|}{ Methods } & $\begin{array}{l}\text { Interactio } \\
\text { n forms }\end{array}$ & \multicolumn{1}{|c|}{ Means } & Technology \\
\hline $\begin{array}{l}\text { Information and } \\
\text { methodological } \\
\text { supervision of } \\
\text { professional and } \\
\text { personal } \\
\text { development }\end{array}$ & discussion & group & forum & discussion \\
\cline { 2 - 5 } & lecture & group & webinar & interactive \\
\cline { 2 - 5 } & talk & individual & case study & \\
\cline { 2 - 5 } & mentoring & individual & online and offline & mentoring \\
\hline $\begin{array}{l}\text { Psychological and } \\
\text { pedagogical } \\
\text { supervision of } \\
\text { professional and } \\
\text { personal } \\
\text { development }\end{array}$ & mentoring in & individual & $\begin{array}{l}\text { online and face-to- } \\
\text { face }\end{array}$ & mentoring \\
\cline { 2 - 5 } & & introspection diary & self-determination \\
\hline $\begin{array}{l}\text { Professional } \\
\text { socialization of a } \\
\text { beginning teacher }\end{array}$ & mentoring & collective & $\begin{array}{l}\text { consolidate } \\
\text { activities }\end{array}$ & project \\
\hline
\end{tabular}

The structure of an in-service teacher supervision web portal is multi-component as it incorporates "Bank of ideas", "Questionnaire", "Proficiency", "Calendar", "Webinars", "Forums", "Library" and "Introspection Diary".

"Bank of ideas" involves a collection of effective solutions, successful teaching hints, ideas worked out by beginning teachers. It gives the opportunity to share effective teaching and classroom management techniques and methods.

"Questionnaire" contains beginning teacher professional motivation diagnostic tools, tools for analysis of internal and external factors of their self-development, of the level of teacher's competence, as well as the degree of adaptation to the professional environment. This element of the in-service supervision web portal is based on a beginning teacher's performance assessment.

"Proficiency" contains video recordings of in- and out-of-school activities performed by a beginning teacher. On-line mentoring technology gives the opportunity to improve a mentee-teacher's skills by discussing and analysing mentee's performance.

"Calendar" is a kind of a roadmap that navigates the mentors and mentees in a timeline. It shows what steps should be taken and when, synchronizes the interaction of all participants of in-service supervision. 
"Webinars" is an interactive methodological platform for a novice teacher. Webinars offer practical approaches to solving problems of teaching. The "Webinars" aims at continuous elaboration in teaching and development of teacher's competence.

"Forums" contains a number of virtual discussions on different topics such as teaching, adaptation of a novice teacher to a professional environment, achievements and difficulties in current professional tasks of other beginning teachers.

"Library" contains two sections: a section for mentors and a section for a beginning teacher. The mentors' section contains information on mentoring technology, methods of conducting a mentoring session and in-service supervision. The section for a beginning teacher contains information on methods of teaching.

"Introspection Diary" allows a young teacher to reflect the degree of satisfaction with their teaching and in-service supervision, to describe experience, achievements and crises, to reflect on working as a teacher.

To evaluate the efficiency of the model of in-service supervision of a novice teacher we have to estimate how efficient a novice teacher is in several key areas. These areas include involvement of a young teacher in a professional environment, establishing contact with students and their parents, and increasing student performance in the classroom.

Establishing contact with colleagues and taking a certain position in an educational environment means a high degree of professional involvement of a beginning teacher. This factor contributes to the adaptation of a young teacher in the profession. Entering the professional environment is an important criterion for the efficiency of in-service supervision of a novice teacher in profession.

Establishing contact with different agents and stakeholders of the educational environment is equally important. It takes a lot of effort to set the positive climate, the teacher-student contact, proper educational relations, and create a team of teachers, students and their parents. That is where the help of an experienced mentor is needed.

The in-service supervision of beginning teachers is efficient if their students demonstrate the increase of their academic performance. This fact was confirmed in the studies of R. Ingersoll [15]. However, the idea about the need for long-term supervision found in some studies [13] turns to be even more significant. For example, a study involving 415 schools and 1,009 teachers showed that the academic performance of the students of the novice teacher improved after only two years of comprehensive supervision. So the duration of the supervision may be an important factor.

\section{Conclusions}

The in-service supervision of a novice teacher is a way of solving a number of important problems. The problems include: the formation of a new generation of teaching staff, overcoming the "outflow" of young professionals, the existence of a "professional elevator" that lets beginning teachers gain professional experience quickly and effectively. An important task solved via the mentoring system at school is to define a new track for the professional career of a teacher-mentor. Since mentoring is an exchange of professional values it certainly contributes to the professional "renewal" of the mentor.

The study revealed the need for systemic changes in order to create a sustainable mechanism of teacher mentoring in the Russian Federation. To meet this need, it is necessary to spread mentoring practice in schools of the regions of the country in cooperation with education universities; to make the supervision system open and accessible for each beginning teacher. It is necessary to form a strategy of in-service supervision. The strategy should be variable and flexible in its content, it should meet the personal requirements of the teachers, but also consider the specific features of the regions. It should create conditions for the support and training of mentors. 
The research prospects are to define the best ways to arrange mentoring and in-service supervision. They include special training for mentors developing their mentoring competencies, the introduction of in-service teacher supervision web portal, allowing a beginning teacher to interact with the university staff mentor and a mentor at school, as well as develop and strengthen teachers' community.

\section{References}

1. C. Kutcy, R. Schulz, Why are beginning teachers' frustrated with the teaching profession, McGill Journal of Education, 41(1), 77-90 (2006)

2. E.N. Agapova, Accompanying the process of adaptation of the initial stage of the teacher's professional activity, Universum: Bulletin of Herzen University, 3, 36-46 (2013)

3. I.I. Cherkasova, Methodological foundations of the concept of management of professional adaptation of young teachers, Modern studies of social problems, 11(19) (2012)

4. A.A. Fedorov, G.A. Paputkova, Employer-sponsored teacher training: a model of a personnel designer of a regional socio-pedagogical cluster, 250 (2017)

5. Teacher Education Ministerial Advisory Group, Classroom Ready Teachers, Canberra, Australia, viewed (2014)

6. The Australian Institute for Teaching and School Leadership, The Australian Professional Standards for Teachers AITSL Melbourne, https://www.aitsl.edu.au/teach/standards

7. D. Mayer, A. Allard, R. Bates, M. Dixon, B. Doecke, J. Kline, A. Kostogriz, J. Moss, L. Rowan, B. Walker-Gibbs, S. White, R. Hodder, Studying the effectiveness of teacher education, Final report (2015)

8. L. Kidd, N. Brown, N. Fitzallen, Beginning Teachers' Perception of Their Induction into the Teaching Profession, Australian Journal of Teacher Education, 40(3), (2015)

9. E.Yu. Ilaltdinova, Problems and foreign experience of technologization of mentoring in teacher's professional development, Problems of modern pedagogical education, $\mathbf{5 3}$ (2016)

10. E.Yu. Ilaltdinova, Features of the organization of in-service supervision of the employer-sponsored teacher training in the context of support of the life cycle of the profession of a teacher, Bulletin of Minin University, 3(20), 2 (2017)

11. A.A. Fedorov, New pedagogical education, Accreditation in education, 8(92), 18-22 (2016) 